\title{
Sensitivity of the Last Glacial Inception to initial and surface conditions
}

\author{
Claudia Kubatzki*, Martin Claussen, Reinhard Calov, Andrey \\ GANOPOLSKI
}

Potsdam Institute for Climate Impact Research, Potsdam, Germany

*kubi@pik-potsdam.de, Fax +49-331 288 2690, Phone +49-331 2882590

\begin{abstract}
We investigate the sensitivity of simulations of the Last Glacial Inception (LGI) with respect to initial (size of the Greenland ice sheet) and surface (state of ocean/vegetation) conditions and two different $\mathrm{CO}_{2}$ reconstructions. Utilizing the CLIMBER-2 Earth system model, we obtain the following results: i) Ice-sheet expansion in North America at the end of the Eemian can be reduced or even completely suppressed when pre-industrial or Eemian ocean/vegetation is prescribed. ii) A warmer surrounding ocean and, in particular, a large Laurentide ice sheet reduce the size of the Greenland ice sheet before and during the LGI. iii) A changing ocean contributes much stronger to the expansion of the Laurentide ice sheet when we apply the $\mathrm{CO}_{2}$ reconstruction according to Barnola et al. (1987) instead of Petit et al. (1999). iv) In the fully coupled model, the $\mathrm{CO}_{2}$ reconstruction used has only a small impact on the simulated ice sheets but it does impact the course of the climatic variables. v) For the Greenland ice sheet, two equilibrium states exist under the insolation and $\mathrm{CO}_{2}$ forcing at 128,000 years before present (128 kyr BP); the one with an ice sheet reduced by about one quarter as compared to its simulated pre-industrial size and the other with nearly no inland ice in Greenland. vi) Even the extreme assumption of no ice sheet in Greenland at the beginning of our transient simulations does not alter the simulated expansion of northern hemispheric ice sheets at the LGI.
\end{abstract}

Glacial Inception Ice Sheets Ocean Vegetation $\mathrm{CO}_{2}$

\section{Introduction}

Reconstructions of sea-level change from corals and oxygen isotope records (e.g. Chappell et al. 1996; Waelbroeck et al. 2002; Siddall et al. 2003) indicate that between about 120 and $115 \mathrm{kyr} \mathrm{BP}$, at the end of the Eemian interglacial, large ice sheets must have started to form in the northern hemisphere. The largest ice sheets developed over North America. According to Clark et al. (1993), they started to form over Keewatin, Quebec, and Baffin Island.

Several modelling attempts exist that try to simulate the expansion of inland ice (often in terms of perennial snow cover) at that time and to determine the factors that led to or at least contributed to the last glacial inception. One idea is that changes in the ocean and vegetation state provide positive feedback to the building of ice sheets at the LGI (e.g. Harvey 1989). There are several equilibrium and transient simulations that explicitly try to quantify the effects of interactive as compared to prescribed ocean and vegetation. Some examples are given in the following.

Dong and Valdes (1995) used the UGAMP Atmospheric General Circulation Model (AGCM) to simulate the end of the Eemian. They performed 
equilibrium simulations using insolation conditions for $115 \mathrm{kyr} \mathrm{BP}$ and an atmospheric $\mathrm{CO}_{2}$ concentration of 280 ppmv. Land-surface albedo and roughness length were prescribed and remained unchanged from the simulation of the present-day climate (which used a $\mathrm{CO}_{2}$ concentration of $345 \mathrm{ppmv}$ ). In one experiment, they prescribed a decrease in summer Sea-Surface Temperatures (SSTs) to the north of $65^{\circ} \mathrm{N}$ and in another, they coupled the AGCM to a mixedlayer ocean model. The results were compared to a simulation for $115 \mathrm{kyr} \mathrm{BP}$ with prescribed present-day SSTs and sea-ice distribution. This comparison indicated that changes in SSTs and sea-ice cover amplify the insolation-induced cooling and this way support the existence of perennial snow cover in several regions.

Khodri et al. (2001) used the AOGCM IPSL-CM2 to simulate the equilibrium climate at $115 \mathrm{kyr} \mathrm{BP}$ with 'the concentration of atmospheric $\mathrm{CO}_{2}$ kept to its present level, as found in the Vostok ice-core record'. Land-surface conditions were left unchanged. The experiment showed strong changes in the meridional atmospheric moisture transport as compared to the present. The authors concluded that especially in the high northern latitudes, ocean feedback strongly amplified the initial cooling at $115 \mathrm{kyr} \mathrm{BP}$ as resulting from the insolation changes and furthermore, added to increase the delivery of snow into these regions. Over the Canadian Archipelago, snow cover became perennial in their simulation.

Vettoretti and Peltier (2004) performed equilibrium simulations with the CCCma AGCM2 for a "cold orbit" and a $\mathrm{CO}_{2}$ concentration of 260 ppmv. No changes in the land surface conditions were applied. Comparison of a simulation with interactive mixed-layer ocean model with a simulation in which SSTs were kept fixed to their modern observed state showed that changes in the ocean surface lead to an increase in snow depth over some islands in the Canadian Arctic.

De Noblet et al. (1996) coupled the LMD-5.3 AGCM with the global biome model BIOME-1.0 using the anomaly approach (i.e. climate anomalies are added to a modern climatology to force the vegetation model). They performed equilibrium simulations for $115 \mathrm{kyr} \mathrm{BP}$, applying a $\mathrm{CO}_{2}$ concentration of 280 ppmv (in contrast to $345 \mathrm{ppmv}$ in the present-day climate simulation). SSTs and sea-ice distribution were prescribed as present. Results were compared to a simulation of $115 \mathrm{kyr}$ BP but with present-day vegetation distribution (simulated as result of a modern climatology). Mainly the summer cooling at $115 \mathrm{kyr}$ BP led to a southward shift of the boreal treeline. Due to the albedo effect, this shift amplified the cooling at $115 \mathrm{kyr} \mathrm{BP}$ and resulted in an increase in snow depth and duration especially in those areas identified as centers of ice-sheet expansion in the data. However, the snow cover did not persist through the summer in their simulations. The present-day warm bias of the model in mid and high northern latitudes is discussed as one potential reason for this.

Gallimore and Kutzbach (1996) showed a similar effect with the NCAR AGCM coupled to a mixed-layer ocean model. In their equilibrium simulations of $115 \mathrm{kyr} \mathrm{BP}$, they increased the surface albedo in the model according to biomemodel estimates for a change in the vegetation distribution. Atmospheric $\mathrm{CO}_{2}$ 
concentration was reduced from 330 in the present-day simulation down to 267 ppmv at $115 \mathrm{kyr}$ BP.

Meissner et al. (2003) ran the UVic Earth system model coupled to a dynamic global vegetation model for $116 \mathrm{kyr} \mathrm{BP}$ insolation and a $\mathrm{CO}_{2}$ concentration of 240 ppmv. Results were compared with another equilibrium simulation of $116 \mathrm{kyr}$ BP but with prescribed vegetation. The authors found that vegetation changes at $116 \mathrm{kyr}$ BP increase the cooling in the high north and allow perennial snow cover in the whole Arctic region. In addition, vegetation changes had a significant impact on the temperatures and sea-ice cover over the North Atlantic indicating strong synergistic effects.

Yoshimori et al. (2002) used the CCCma AGCM to investigate both the role of the land as well as the ocean surface. They performed equilibrium simulations for $116 \mathrm{kyr} \mathrm{BP}$ and a $\mathrm{CO}_{2}$ concentration of $240 \mathrm{ppmv}$. They prescribed SSTs and sea-ice cover from equilibrium simulations (performed with a coupled model of intermediate complexity but not with the AGCM itself) for either present-day (with a $\mathrm{CO}_{2}$ concentration of $350 \mathrm{ppmv}$ ) or $116 \mathrm{kyr} \mathrm{BP}$ climate. Vegetation cover was kept to its observed present-day state. In a second step, they diagnosed changes in tundra areas (parameterised as being dependent on temperature) from these two AGCM simulations and prescribed them in two additional simulations of $116 \mathrm{kyr}$ BP climate. They conclude that changes in the ocean and in the vegetation cover result in an expansion of the perennial snow cover, the impact of the vegetation occuring mainly when the ocean is in its cooler 116 kyr BP state.

Crucifix and Loutre (2002) used the Earth system model of intermediate complexity MoBidiC to run transient simulations from 126 to $115 \mathrm{kyr} \mathrm{BP}$. They applied insolation changes but fixed the atmospheric $\mathrm{CO}_{2}$ concentration to 261 ppmv. The results were compared to transient simulations in which the vegetation and ocean characteristics, respectively, were fixed to their state as simulated for $126 \mathrm{kyr}$ BP. The authors concluded that changes in vegetation/ocean and sea ice strongly contribute to an increase in perennial coverage of both, snow on land and Arctic sea ice and to an expansion of tundra and cold desert, respectively. In addition, the surface changes impact the timing of the environmental changes. Wang and Mysak (2002) presented transient simulations from 120 to $110 \mathrm{kyr}$ BP with the MPM coupled to a two-dimensional ice-sheet model. They applied not only the insolation changes but also the varying atmospheric $\mathrm{CO}_{2}$ concentration according to Barnola et al. (1999). Fixing the SSTs in their simulation to their initial values reduced the simulated global ice volume by about $24 \%$, mainly because of a reduced Laurentide ice sheet.

Kageyama et al. (2004) used CLIMBER-2 coupled to the GREMLINS northern hemisphere ice-sheet model to perform simulations from 126 to $106 \mathrm{kyr}$ BP using the $\mathrm{CO}_{2}$ concentration according to Petit et al. (1999). They initiated their simulations with results from an equilibrium simulation of $126 \mathrm{kyr}$ BP with a prescribed present-day ice sheet. The authors compared the results of their fully coupled simulation with those of a simulation with prescribed vegetation as resulting from the $126 \mathrm{kyr} \mathrm{BP}$ equilibrium run. Whereas the simulation with interactive vegetation results in extended inland ice in North America, no substantial ice-sheet expansion occurs in the fixed-vegetation run. 
There are several conclusions that can be drawn from the simulations discussed above.

1. Comparison of simulations with interactive and with fixed surface characteristics showed that the state of ocean and vegetation has an impact on the simulation of the LGI.

2. In many of the publications discussed above, either ocean or vegetation is interactive, not both of them. In fact, ocean and vegetation are fixed to all different states: present-day observed (or diagnosed from the present-day climatology); present-day simulated (with $\mathrm{CO}_{2}$ concentrations of about 330 to 345 ppmv); pre-industrial (with $\mathrm{CO}_{2}$ concentrations of about 240 to 280 ppmv); or Eemian. This makes it difficult not only to compare the different studies but also to estimate what quantitative impact ocean and vegetation, respectively, have on the simulation of the LGI.

3. Although work was done on the impact of different fixed $\mathrm{CO}_{2}$ values as well as of different $\mathrm{CO}_{2}$ reconstructions on the climatic changes during the last glacial cycle (e.g. Berger et al. 1998), the impact of vegetation and ocean on the simulation of the LGI under available $\mathrm{CO}_{2}$ reconstructions remains unclear.

In this study, we want to add on these points by performing transient simulations of the LGI with an Earth system model of intermediate complexity (including a coupled inland-ice model). We use two $\mathrm{CO}_{2}$ reconstructions that differ by a few thousand years in the timing of the major $\mathrm{CO}_{2}$ drop at the LGI. We prescribe surface conditions as simulated by the model for a warm (Eemian) as well as a colder (pre-industrial) climate. Results are compared with a simulation with interactive ocean and vegetation.

Berger et al. (1998) showed that the size of ice sheets used to initiate a model run was relevant for the simulation of the last glacial-interglacial cycle. In their simulations, the ice sheet assumed at $122 \mathrm{kyr}$ BP determines to what extent northern hemispheric ice sheets exist at $100 \mathrm{kyr}$ BP. From the above, the question arises what initial size for the Greenland ice sheet should be assumed in transient simulations of the LGI.

Sea-level reconstructions from corals and oxygen isotope records indicate that the global sea level during the Eemian was up to $10 \mathrm{~m}$ above its present level (e.g. Chappell et al. 1996; Stirling et al. 1998; Waelbroeck et al. 2002; Siddall et al. 2003). It is unclear to what extent the Greenland and the West Antarctic ice sheet contributed to this relative sea-level rise (e.g. Cuffey and Marshall 2000) but there is agreement that the Greenland ice sheet was smaller during the Eemian than at present. Recently, the North Greenland Ice Core Project (NGRIP) members (2004) discussed the climate record of the late Eemian period, especially changes in the thickness of the Greenland ice sheet as well as local temperature changes. The size of the Greenland ice sheet under future climate change is still under debate. In particular, Crowley and Baum (1995) raised the question of multi-stability of the Greenland ice sheet with a second, ice-free state.

In our work, the size of the Greenland ice sheet at the Eemian and its role in the transient simulation of the LGI will be discussed as well as the question of multi-stability. Not only in this respect, this paper adds on simulations recently performed by Calov et al. (2005a/b) with the Earth system model of intermediate 
complexity, CLIMBER-2. In our work, we will additionally investigate the effect of prescribing different land and ocean surface conditions and, in particular, different $\mathrm{CO}_{2}$ reconstructions on the simulation of the LGI. Furthermore, the impact of an ice sheet over North America on the size of the Greenland ice sheet is explored.

\section{The model}

All simulations described below have been performed with the Earth system model of intermediate complexity CLIMBER-2.

The atmospheric part of CLIMBER-2 (version 3) consists of a statisticaldynamical model (Petoukhov et al. 2000). Its resolution is $10^{\circ}$ in latitude and about $51^{\circ}$ in longitude with up to 16 vertical levels (for the radiation scheme). The ocean model (similar to Stocker et al. 1992) consists of threebasins with a latitudinal resolution of $2.5^{\circ}$ and 20 unequally thick layers in the vertical. Attempts are made to account for fractional sea-ice cover and east-west gradients in sea-surface conditions within one ocean box and its related atmospheric grid boxes (for details see Petoukhov et al. 2000). A thermodynamic sea-ice model is included. The three ocean basins are linked in the circumpolar regions. Landsurface processes are simulated on the atmospheric resolution. The continuous dynamic global vegetation model VECODE (Brovkin et al. 2002) describes potential fractions of tree, grass, and bare soil coverage; changes of which, for illustration, can be transferred into shifts of vegetation zones in terms of kilometres assuming homogenous vegetation distribution within the grid box. Vegetation affects surface albedo, evapotranspiration and soil moisture and, via its roughness, has an effect on turbulent fluxes and near-surface winds. Background values for tree albedo amount to 5 and $20 \%$, values for grass albedo amount to 8 and $30 \%$ for visible and near-infrared radiation, respectively. Soil albedo values are 15 and $30 \%$ (22 and $45 \%$ for the Sahara). The snow-masking effect of vegetation depends on snow depth. Surface fluxes are calculated separately for the individual surface types and than averaged for the (atmospheric) grid box. To test the impact of ocean or vegetation on climate both, the ocean as well as the vegetation model can be coupled interactively or the respective surface characteristics (SSTs and sea-ice fraction and thickness; fractions of trees, grass, and bare soil and leaf-area indexes for trees and grass) can be prescribed according to the results of previous model simulations. CLIMBER-2 has already been used in a number of climate sensitivity studies, palaeoclimate simulations and future climate change projections (e.g. Ganopolski et al. 1998a/b; Brovkin et al. 1999; Claussen et al. 1999; Rahmstorf and Ganopolski 1999; Kubatzki et al. 2000; Ganopolski et al. 2001; Calov et al. 2005a/b). Detailed model validation is given in Petoukhov et al. (2000) showing that in general, the model performance for present-day climate is reasonable in comparison to observational data.

CLIMBER-2 includes the three-dimensional polythermal ice-sheet model SICOPOLIS (Greve et al. 1997) for the northern hemisphere extratropics, running on a resolution of $0.75^{\circ}$ in latitude and $1.50^{\circ}$ in longitude. Here, the model simulates the ice extent, thickness, temperature, velocity, and water content. To match the coarser resolution of the rest of the model, an interface module has been developed for direct interactive coupling (for details see Calov et al. 2005a). It provides the inland-ice model with annual values of mass balance and surface 
temperature. SICOPOLIS returns inland-ice fraction, surface elevation, and sealevel change. Variations of the deposition of mineral dust were taken into account for the calculation of snow albedo (for details see Calov et al. 2005a/b). CLIMBER-2 including the inland-ice model has been used not only to investigate the LGI (Calov et al. 2005a/b) but also Heinrich events (Calov et al. 2002). Inland ice in a simulation using pre-industrial $\mathrm{CO}_{2}$ is mainly found in Greenland, Svalbard, Island, and parts of Scandinavia. In Canada, very few spots with inland ice are simulated. The simulated area of inland ice in the northern hemisphere amounts to $2.8 \times 10^{6} \mathrm{~km}^{2}$. Its distribution compares reasonably with observations, the Greenland ice volume is overestimated to some extent (a detailed comparison with observations can be found in Calov et al. 2005a). A wet bias exists in the coupled climate-ice sheet model for present-day climate, in particular in northeastern Eurasia and also in northern North America and mainly during summer. The bias is thus smaller for winter snow thickness. Reason and effect of this are discussed in Calov et al. (2005a).

\section{Sensitivity to initial conditions}

\section{Equilibrium runs of the Eemian interglacial}

As a first step to investigate the LGI, we need to simulate the climate at the Eemian interglacial. This will give us the initial conditions needed for the transient simulations presented later on. For this purpose, we performed a 200-kyr long equilibrium simulation EQ128k of the fully coupled model for $128 \mathrm{kyr} \mathrm{BP}$ (see Tab. 1). Orbital parameters were prescribed according to Berger (1978) and the $\mathrm{CO}_{2}$ concentration was $277 \mathrm{ppmv}$ (Petit et al. 1999). $128 \mathrm{kyr} \mathrm{BP}$ was chosen as it shows about the highest maximum summer insolation at $65{ }^{\circ} \mathrm{N}$ for the Eemian (see Fig. 1). The simulation was initiated using the equilibrium simulation CTR of the pre-industrial climate (see Tab. 1). In CTR, the size of the Greenland ice sheet amounts to about $2.5 \times 10^{6} \mathrm{~km}^{2}$ (see Fig. 2), the ice volume amounts to $4.6 \times 10^{6} \mathrm{~km}^{3}$.

The $\mathrm{CO}_{2}$ concentration in EQ128k was about 3 ppmv lower than in CTR. Nevertheless, the climate at $128 \mathrm{kyr} \mathrm{BP}$ was about $0.6{ }^{\circ} \mathrm{C}$ warmer and $0.1 \mathrm{~mm} /$ day wetter on global annual average than the pre-industrial climate as result of differences in the orbital configuration. At $128 \mathrm{kyr} \mathrm{BP}$, summers in the northern hemisphere were warmer and the growing season was longer (for more details see results with an early version of our model in Kubatzki et al. 2000). Accordingly, boreal forests extended further to the north and the northern hemispheric annual sea-ice area was about $2.6 \times 10^{6} \mathrm{~km}^{2}$ smaller than for the pre-industrial climate where its size was $9.7 \times 10^{6} \mathrm{~km}^{2}$ (compare with Fig. 3a/b). The difference in northern hemisphere annual mean surface albedo between EQ128k and CTR amounts to $-1.7 \%\left(-5.1 \%\right.$ to the north of $50{ }^{\circ} \mathrm{N}$; differences are given as absolute values, e.g. $-1.7 \%$ is the difference between $15.0 \%$ for Eemian and $16.7 \%$ for pre-industrial climate). This albedo difference results not only from differences in sea ice and vegetation cover but also from changes of the Greenland ice cover.

In EQ128k, the Greenland ice sheet has time to equilibrate to the warm climate at $128 \mathrm{kyr}$ BP. Real ice sheets at $128 \mathrm{kyr}$ BP were certainly not in equilibrium with climate and thus do not necessarily reflect the warmest phase of the Eemian. On the other hand, NGRIP members (2004) explicitly discuss data for 
the warmest part of the Eemian in Greenland. As the equilibrium simulation EQ128k reflects the highest boreal summer insolation phase of the Eemian, it is instructive to compare results of this simulation with the NGRIP record to get an idea of the reasonableness of our model results. The simulated Greenland ice area at $128 \mathrm{kyr} \mathrm{BP}$ is smaller than for pre-industrial climate and amounts to about $1.8 \mathrm{x}$ $10^{6} \mathrm{~km}^{2}$ (see Fig. 2). This is the main reason for the reduced mean ice volume that amounts to about $3.3 \times 10^{6} \mathrm{~km}^{3}$. The simulated ice thickness at $128 \mathrm{kyr} \mathrm{BP}$ is reduced mainly at the ice-sheet margins and especially in the southern parts of Greenland. This picture is consistent with results of the NGRIP members (2004) for the warmest part of the Eemian climate.

From the stable oxygen isotopic record, the NGRIP members (2004) estimate at least a $5 \mathrm{~K}$ warmer temperature in the Eemian than at present'. The isotopic value difference between the present and the Eemian period is similar for all the northern Greenland ice cores but is larger for the Dye 3 ice core in southern Greenland where the authors suggest a lower elevation and thus higher temperatures for the Eemian. In EQ128k, annual temperatures averaged over Greenland are about $4{ }^{\circ} \mathrm{C}$ higher than in CTR. The largest temperature changes are found in the areas where ice thickness is most strongly reduced.

To address the question of multi-stability of the Greenland ice sheet as for example raised by Crowley and Baum (1995) for the future climate, we performed a second equilibrium simulation for 128 kyr BP, EQ128k_0 (see Tab. 1). Recall that the simulation EQ128k was initiated with a modelled pre-industrial Greenland ice-sheet. In EQ128k_0, the model was initialised with no inland ice at all in the northern hemisphere. In this simulation, even after $200 \mathrm{kyr}$ of integration the size of the Greenland ice sheet amounts to only about $0.1 \times 10^{6} \mathrm{~km}^{2}$ (see Fig. 2 ). The few inland-ice spots are mainly located in the southern and eastern part of the island. Caused by the initial albedo and elevation differences, regional temperatures remain several degrees higher than in EQ128k, especially in summer. In addition, temperatures stay above zero for a longer time of the year, preventing the ice sheet from further growing.

In conclusion, Greenland nearly without ice is a second equilibrium solution for the full interglacial conditions at $128 \mathrm{kyr}$ BP in our model. Thus, according to the model, the existence of inland ice in Greenland during the Eemian as indicated by the data is a consequence of the previous cold stage.

\section{Transient runs of the Last Glacial Inception}

To investigate the impact of different initial conditions on a transient simulation of the LGI, we performed two simulations with the fully coupled model. Firstly, we used results of our equilibrium simulation EQ128k as initial condition for the transient run AOVI (see Tab. 1). The model was driven by changes in the orbital parameters for 128 to $100 \mathrm{kyr} \mathrm{BP}$ following Berger (1978) from which the latitudinally and seasonally varying insolation was computed. Work in progress (not shown here) suggests that the mass balance of inland ice reveals the highest correlation with maximum summer insolation at $65^{\circ} \mathrm{N}$. This insolation value declines from the Eemian onwards, reaches its minimum around $116 \mathrm{kyr} \mathrm{BP}$, increases again towards $105 \mathrm{kyr} \mathrm{BP}$ and then again starts to decrease (see Fig. 1). In addition to the insolation changes, changes in the atmospheric $\mathrm{CO}_{2}$ concentration were prescribed according to Petit et al. (1999). 
Fig. 4a/b show the climate response to the forcing. In the transient run, glacial inception in terms of rapid ice-sheet expansion over North America takes place at about $117.5 \mathrm{kyr}$ BP. Maximum boreal summer insolation has dropped below a certain threshold after which the bifurcation transition occurs. The rapid glacial inception is result of a strong positive snow-albedo feedback (the dynamics of the last glacial inception in CLIMBER-2 are described in detail in Calov et al. 2005a). The largest ice sheet develops over North America (see Fig. 5) and is mainly responsible for the sea-level drop of about $40 \mathrm{~m}$. Main ice-sheet development in North America starts in northern Quebec and in Baffin Island. Its evolution is in general similar to what is described from reconstructions (e.g. Clark et al. 1993). Global annual temperature drops by about $1.5{ }^{\circ} \mathrm{C}$, the contribution of the $\mathrm{CO}_{2}$ amounts to about $0.7{ }^{\circ} \mathrm{C}$ to the end of the simulation (this was found from simulations separating the insolation and the $\mathrm{CO}_{2}$ effect; they are not further discussed here).

We tested the impact of different initial conditions on the simulation of the LGI with another model run. Simulation AOVI_0 was initialised again with the simulation EQ128k but assuming no inland ice in the northern hemisphere (see Tab. 1).

Fig. 6a shows that the simulation of the LGI is rather robust against the different initial conditions. When starting our model with no inland ice in the northern hemisphere at $128 \mathrm{kyr} \mathrm{BP}$, the Greenland ice sheet starts to develop mainly after about 123 kyr BP (see Fig. 6b). This means that the insolation supports the second, nearly ice-free equilibrium state for Greenland only in a short interval around $128 \mathrm{kyr}$ BP. In AOVI_0, the Greenland ice sheet reaches its full size (i.e. catches up with simulation AOVI) about 2000 years after the insolation minimum was passed. At about $117.5 \mathrm{kyr}$ BP, the Greenland ice sheet in AOVI_0 is not yet fully developed. As result, the land areas to the north of $60{ }^{\circ} \mathrm{N}$ are about $0.3{ }^{\circ} \mathrm{C}$ warmer on annual average than in AOVI, mainly because of the albedo difference. Due to the warmer conditions, the glacial inception in North America is delayed by about 500 years but it still takes place with the same rapidity, and strength as in AOVI and the ice sheet reaches very similar areal extension. Differences in the ice area between the two simulations remain below $0.5 \times 10^{6}$ $\mathrm{km}^{2}$.

In conclusion, because of its comparably small size and its location downstream of the Laurentide ice sheet, even the extremely different assumptions for the initial Greenland ice sheet have no effect on the characteristics of the LGI in our model and only slightly affect the timing of the Laurentide ice-sheet development.

\section{Sensitivity to surface conditions}

\section{Modern ocean and vegetation}

To investigate the impact of fixed pre-industrial as compared to interactive surface conditions, we performed three simulations AVI0, AOI0, and AI0 (see Tab. 1). They are identical with the simulation AOVI except that ocean and/or vegetation characteristics were prescribed according to simulation CTR. 
As can be seen from Fig. 7a, surface changes strongly influence the amount of inland ice that builds up in North America at the LGI. The impact of ocean and of vegetation feedback on size of the Laurentide ice sheet is comparable in these simulations. If only either ocean (in AOI0) or vegetation (in AVI0) is allowed to adapt to a changing climate, the ice-sheet area is reduced by about one half in comparison to the fully coupled simulation AOVI. If both, ocean and vegetation are prescribed in $\mathrm{AI} 0$, the ice sheet extent is additionally diminished by roughly $1 \times 10^{6} \mathrm{~km}^{2}$.

Comparison of the four curves in Fig. 7 a reveals that the respective impacts of ocean and of vegetation feedback do not linearly add to give the response of the fully coupled model. In AOVI, there is a synergistic effect due to the ocean and the vegetation feedback amplifying each other. In AVI0, AOI0, and AI0, pre-industrial surface conditions are prescribed. As discussed in the previous chapter, pre-industrial climate is colder than the Eemian climate but it is warmer than the climate at the LGI. As is also reflected by Fig. 8a, fixing the surface conditions to their pre-industrial state means a cooling at the beginning but a warming in the later stage of our transient simulations. Just before the LGI at about $118 \mathrm{kyr} \mathrm{BP}$, the annually averaged northern hemispheric sea-ice area in AOIO is increased by about $1.4 \times 10^{6} \mathrm{~km}^{2}$ as compared to AIO which increases reflectance, and thus radiative heat loss. In AVI0, just before the LGI the boreal forest in North America retreats southwards by more than $200 \mathrm{~km}$ as compared to AI0, which increases albedo, and thus also radiative heat loss. This way both, interactive ocean and vegetation amplify the insolation-induced cooling and thus support glacial inception. Both feedback processes most strongly act at higher latitudes and amplify each other in the fully coupled simulation. At $118 \mathrm{kyr}$ BP, the annually averaged northern hemispheric sea-ice area in AOVI additionally increases by $0.3 \times 10^{6} \mathrm{~km}^{2}$ as compared to AOI0 and the boreal forest in North America retreats by another nearly $300 \mathrm{~km}$ as compared to AVI0. Similar synergistic effects in the model have been described in Ganopolski et al. (1998) and Brovkin et al. (2003), and have been analysed in terms of feedback factors in Kubatzki et al. (2000) and Claussen (2001) but have also been suggested by other authors (e.g. Bonan et al. 1992; Berger 2000).

From Fig. 7a it is obvious that the number of components of the climate system has an impact also on the timing of the LGI. The onset of the rapid expansion of the Laurentide ice sheet can be delayed by more than 1000 years as soon as ocean and/or vegetation are fixed to their pre-industrial state and thus the system is kept in warmer conditions. As soon as the ice sheet starts to develop, there is an additional factor coming into play which is the feedback through inland ice and the synergy related to this.

\section{Eemian ocean and vegetation}

We addressed the question of the reference state by repeating the simulations of the previous section but prescribing surface conditions according to the simulation EQ128k (AVI128; AOI128; AI128, see Tab. 1). As discussed above, Eemian instead of pre-industrial surface conditions (see Fig. 3) keep the climate system in a warmer state. In contrast to the simulations with fixed pre-industrial ocean and vegetation where global climate immediately gets colder at the beginning of the simulation (see Fig. 8a), the simulations with fixed Eemian surface conditions remain warmer (see Fig. 8b). (Fig. 8 also indicates that the interactive vegetation 
in AVI0 and AVI128 transfers the precessional signal and thus seasonal insolation changes into an annual temperature signal. In the simulation AOI0 and AOI128 with interactive ocean, the $\mathrm{CO}_{2}$ signal is reflected more strongly; compare with Fig. 1.)

At $118 \mathrm{kyr} \mathrm{BP}$, just prior to the LGI, the difference in annual surface albedo between AI128 and AIO in the northern hemisphere amounts to about -1.8 $\%\left(-5.2 \%\right.$ to the north of $\left.50{ }^{\circ} \mathrm{N}\right)$. The albedo difference between AVI128 and AVI0 for the fixed-ocean runs amounts to $-0.8 \%(-3.5 \%)$ and the difference between AOI128 and AOI0 for the fixed-vegetation runs amounts to $-1.5 \%$ (-3.6 $\%)$ at that time. As a consequence, the net shortwave radiation input at the Earth's surface is higher in all simulations prescribing Eemian ocean and vegetation. Over North America, the net annual gain is up to $8 \mathrm{~W} / \mathrm{m}^{2}$ at $118 \mathrm{kyr} \mathrm{BP}$ and north of 50 ${ }^{\circ} \mathrm{N}$. As result, prescribing Eemian instead of pre-industrial ocean and/or vegetation conditions prevents nearly any ice-sheet expansion in North America (see Fig. $7 \mathrm{c})$.

It is interesting to have a closer look on the Greenland ice sheet (see Fig. $7 \mathrm{~b} / \mathrm{d}$ ). Prior to the LGI, fixing vegetation or prescribing pre-industrial surface conditions has nearly no impact on the size of the Greenland ice sheet as compared to the fully coupled model run AOVI. On the other hand, prescribing SSTs and sea ice according to its warmer Eemian state immediately results in a reduction of the size of the Greenland ice sheet (see green and red curve in Fig. $7 d$ ). In other words, a changing ocean does have a noticeable impact on the ice sheet.

After about $117.5 \mathrm{kyr} \mathrm{BP}$, in the simulations with fixed Eemian surface conditions the Greenland ice sheet is still strongly determined by changing insolation (see coloured curves in Fig. 7d). When pre-industrial ocean as well as vegetation conditions are applied in AI0, a rather large Laurentide ice sheet as compared to AI128 develops. This leads to a reduction of precipitation in Greenland and thus a stronger shrinking of the Greenland ice sheet (see red curve in Fig. 7b) than in the simulations with fixed Eemian surface conditions, despite lower temperatures. The drying over Greenland is result of two factors. The air over North America gets dryer the larger the Laurentide ice sheet grows. Northwesterly winds transporting the dry air towards Greenland are increasing in strength over North America and to the south of Greenland. The more components are coupled, the larger the Laurentide ice sheets grows and the smaller the Greenland ice sheet gets (see blue, green, and black curves in Fig. 7b) despite the more and more cold conditions. In the fully coupled run, the Greenland ice sheet at $100 \mathrm{kyr}$ BP is even smaller than during the Eemian.

\section{The role of $\mathrm{CO}_{2}$}

To investigate the role of the surface conditions under different $\mathrm{CO}_{2}$ forcings, we repeat our simulations with fixed pre-industrial ocean and/or vegetation as well as the fully coupled model run but using the $\mathrm{CO}_{2}$ reconstruction according to Barnola et al. (1987) (simulations with appended '_bar' in notation, see Tab. 1) instead of Petit et al. (1999). Both reconstructions show interglacial $\mathrm{CO}_{2}$ values of about 280 ppmv and values of about 230 ppmv for the later part of the simulation period (see Fig. 1). The remarkable difference between the two data sets is that 
according to Barnola et al. (1987), the major $\mathrm{CO}_{2}$ drop appears already a few thousand years earlier than according to Petit et al. (1999) and thus only a short time after the insolation minimum. The two reconstructions differ noticeably in the time span between about 117 and $108 \mathrm{kyr}$ BP.

The earlier $\mathrm{CO}_{2}$ drop in the Barnola et al. (1987) reconstruction falls close to the insolation minimum and thus supports a stronger cooling around the LGI (see Fig. 9a). Globally averaged annual temperature in the fully coupled model run AOVI using the reconstruction according to Petit et al. (1999) remains on a rather constant level after the LGI. The temperature in the fully coupled run AOVI_bar using the data according to Barnola et al. (1987) on the other hand reveals a pronounced minimum around $114 \mathrm{kyr} \mathrm{BP}$. At that time, annual temperatures in AOVI_bar are about $0.5{ }^{\circ} \mathrm{C}$ lower on global as well as northern hemisphere average than in AOVI.

Correspondingly, the Laurentide ice sheet in AOVI_bar is growing larger by about $5 \%$ at its maximum than in AOVI (see Fig. 9b). In fact, the Laurentide ice sheet grows larger as well in AVI0_bar, AOI0_bar, and AI0_bar than in AVI0, AOI0, and AI0, respectively (compare Fig. 9b with Fig. 7a). However, there is a qualitative difference between the simulations using the one or the other $\mathrm{CO}_{2}$ reconstruction. When the Petit et al. (1999) data are applied together with preindustrial surface conditions, the impact of ocean and of vegetation on the Laurentide ice sheet is comparable as discussed in the previous chapter. This picture changes as soon as the Barnola et al. (1987) data are used. The early $\mathrm{CO}_{2}$ drop there results in an atmospheric cooling around the LGI, in particular in the Arctic, which also sets the ocean surface here into a colder state. Lower SSTs and a more extended sea-ice cover support the cooling and finally ice-sheet expansion. In sum, the impact of an interactive ocean on the Laurentide ice-sheet gets much stronger in case of the Barnola et al. (1987) data used than with the Petit et al. (1999) data and is no longer comparable to that of interactive vegetation.

In conclusion, the fact that ocean and vegetation changes have a crucial impact on the LGI is a robust result in our model. However, the relative impact of a changing ocean and vegetation on the development of the Laurentide ice sheet depends on the course of the atmospheric $\mathrm{CO}_{2}$.

When Eemian instead of pre-industrial surface conditions are applied, glacial inception is inhibited as shown in the previous chapter (see Fig. 7c). This result is robust with respect to the $\mathrm{CO}_{2}$ reconstruction used (not shown here).

\section{Summary and discussion}

We used the Earth system model of intermediate complexity, CLIMBER-2 to investigate the sensitivity of simulations of the LGI with respect to initial and surface conditions and two different $\mathrm{CO}_{2}$ reconstructions. We obtained the following results.

1. For the orbital parameters and $\mathrm{CO}_{2}$ concentration at $128 \mathrm{kyr} \mathrm{BP}$, two equilibrium states exist in the model. One with a Greenland ice sheet reduced by about $0.7 \times 10^{6} \mathrm{~km}^{2}$ in its size as compared to its simulated present-day extent and another one with nearly no inland ice in Greenland. 
2. Our transient simulation of the LGI is insensitive to the initial size of the Greenland ice sheet at 128 kyr BP.

3. Prescribing pre-industrial ocean and/or vegetation characteristics in our simulations significantly dampens the expansion of the Laurentide ice sheet at the LGI. When surface conditions representing the warmer Eemian climate are prescribed, no glacial inception takes place at all.

4. The size of the Greenland ice sheet depends on the size of the Laurentide ice sheet (by means of a reduction in precipitation) and on the state of the surrounding ocean in our simulations. The warmer the ocean and the larger the Laurentide ice sheet, the smaller is the Greenland ice sheet in our simulations.

5. The relative impact of ocean and vegetation changes on the development of the Laurentide ice sheet depends on the $\mathrm{CO}_{2}$ reconstruction applied. An earlier $\mathrm{CO}_{2}$ drop strengthens the role of a changing ocean.

6. In the fully coupled model run, the size of the Laurentide ice sheet differs by only a few percent depending on the $\mathrm{CO}_{2}$ reconstruction used. The $\mathrm{CO}_{2}$ does, however, have a noticeable impact on the course of climatic variables like, e.g., temperatures.

Crowley and Baum (1995) discussed the bi-stability of the Greenland ice sheet under present-day surface conditions. In our simulations, a second, nearly ice-free equilibrium state exists for Greenland for the insolation and $\mathrm{CO}_{2}$ at 128 kyr BP. The geological evidence clearly indicates the existence of a Greenland ice sheet at the Eemian (e.g. NGRIP members 2004). According to our results, this is a consequence of the previous cold stage. Maximum summer insolation at $65^{\circ} \mathrm{N}$ is nearly $70 \mathrm{~W} / \mathrm{m}^{2}$ higher at $128 \mathrm{kyr} \mathrm{BP}$ than at present (see Fig. 1). This suggests that for present-day climate conditions, the nearly ice-free equilibrium state for Greenland might not exist in our model. In fact, this was shown in the simulations of Calov et al. (2005a).

When discussing bi-stability for the Greenland ice sheet, the (coarse) spatial resolution of our model should be taken into account. The high resolution of the inland-ice model allows for a detailed investigation of the Greenland ice sheet. The climatic signal is transferred from the coarse-resolution CLIMBER-2 model though where Greenland is represented by only two grid-boxes. While it is impossible to rule out completely that bi-stability is an artefact of climate model resolution, it is, however, rather unlikely. Greenland not only corresponds to two CLIMBER grid cells, but it occupies only a fraction of these grid cells (50 and $30 \%$ ). This is why the ice-albedo feedback associated with the Greenland ice sheet is underestimated in the model. The primary reason for bi-stability is the elevation effect (or feedback) of ice sheets which operates on the high resolution of our ice-sheet model. It is also important to note that bi-stability of Greenland exists in our model only in a certain range of orbital forcings (or $\mathrm{CO}_{2}$ concentration). As mentioned above, for the present-day orbital configuration and $\mathrm{CO}_{2}$, only one equilibrium state, ice-covered Greenland, can be seen (Calov et al. 2005a).

Coral data indicate a sea-level rise after about $110 \mathrm{kyr}$ BP (e.g. Chappell et al. 1996; Siddall et al. 2003). The LLN 2-D climate model of Berger et al. (1998) shows a strong sensitivity with respect to changes in precession. As result, their model tends to overestimate the amount of sea-level rise after $110 \mathrm{kyr}$ BP. CLIMBER-2 on the other hand tends to underestimate the amount of sea-level rise 
after 110 kyr BP. Berger et al. (1998) show that whether their northern hemispheric ice sheets are completely melted at about $100 \mathrm{kyr}$ BP depends not only on the atmospheric $\mathrm{CO}_{2}$ concentration but also on the size of the Greenland ice sheet they assume at the beginning of their simulation at $122 \mathrm{kyr}$ BP. Assuming a volume of the ice sheet of 0.0 or $1.7 \times 10^{6} \mathrm{~km}^{3}$ at $122 \mathrm{kyr}$ BP results in a northern hemispheric ice-volume difference of about $3.0 \times 10^{6} \mathrm{~km}^{3}$ at $110 \mathrm{kyr}$ $\mathrm{BP}$ in their simulations. When we assume an ice-sheet volume of 0.0 or $3.3 \times 10^{6}$ $\mathrm{km}^{3}$ at $128 \mathrm{kyr}$ BP (in AOVI_0 and AOVI, respectively), we result in a northern hemispheric ice-volume difference of only about $1.6 \times 10^{6} \mathrm{~km}^{3}$ between the two simulations at $110 \mathrm{kyr}$ BP.

Obviously, the coarse spatial resolution of our model must lead to some difficulties for simulations of the LGI in general which can be solved by our downscaling interface only to some extent. First of all, this concerns the atmospheric grid as already mentioned. But also the representation of ice-sheet topography in the coarse-resolution climate component of our model is rather crude and the model lacks topographic waves in the atmosphere. Thus, the dynamical interaction between Laurentide and, especially, Greenland topography and atmospheric circulation is likely to be underestimated. The effect of unresolved topography for initial ice-sheet growth, as for example discussed by Marshall and Clarke (1999), is a matter for any simulation of glacial inception and also concerns albedo and elevation feedbacks. With respect to CLIMBER-2, this issue has been investigated by Calov et al. (2005a) and will be more extensively analysed in a forthcoming paper. Finally, especially quantitative model estimates on the ocean impact should be treated with care as east-west SST gradients are not explicitly simulated in the ocean model.

Our simulations support the idea brought up in earlier work (e.g. Harvey 1989; Dong and Valdes 1995; de Noblet et al. 1996; Gallimore and Kutzbach 1996; Khodri et al. 2001; Crucifix and Loutre 2002; Wang and Mysak 2002; Yoshimori et al. 2002; Meissner et al. 2003; Kageyama et al. 2004; Vettoretti and Peltier 2004) that ocean and vegetation changes support the expansion of areas covered by perennial snow or inland ice at the LGI. As discussed in the introduction, the different authors used all different surface conditions, ranging from pre-industrial to present-day and Eemian. This inconsistency makes the different results impossible to compare quantitatively. Calov et al. (2005b) found a reduced glacial inception with prescribed pre-industrial ocean and/or vegetation surface. In addition to their work, we showed that prescribing Eemian surface conditions in the same model can even completely suppress the glacial inception. The latter result is in agreement with recent findings of Kageyama et al. (2004). It should be noticed that in their fully coupled model run inland-ice expansion at the course of the LGI is much weaker than in our simulation AOVI. Whereas we obtain a maximum northern hemispheric ice-volume of more than $20 \times 10^{6} \mathrm{~km}^{3}$ (corresponding to a sea-level drop of about $40 \mathrm{~m}$ as maximum during the LGI), Kageyama et al. (2004) obtain only some $10 \times 10^{6} \mathrm{~km}^{3}$. This difference appears mainly because the Laurentide ice sheet in our model reaches $55^{\circ} \mathrm{N}$ over large parts of Northern America (that is roughly $10^{\circ}$, i.e. about one latitudinal step in the atmospheric model part of CLIMBER-2 further south than in the simulations of Kageyama et al. 2004) and also because in our model, a little Fennoscandian ice sheet can develop at the end of the Eemian (see Fig. 5). The difference in 
northern hemispheric ice volume as compared to Kageyama et al. (2004) is reduced by the fact that in our simulations, northern Alaska remains ice-free.

Our simulations illustrate the threshold character of the LGI as simulated with CLIMBER-2. When fixing ocean characteristics and vegetation cover, climate model simulations neglect parts of the real climate feedbacks. In case of the LGI this leads to an underestimation of the cooling prior to inception. In our fully coupled transient simulation, glacial inception happens only short time before the boreal summer insolation again starts to increase and the neglect of internal feedbacks by prescribing the surface boundaries is sufficient to prevent it from that.

Calov et al. (2005b) showed that glacial inception is simulated with CLIMBER-2 even with the atmospheric $\mathrm{CO}_{2}$ concentration fixed to its interglacial value of $280 \mathrm{ppmv}$. In our fully coupled simulations, the application of two different $\mathrm{CO}_{2}$ reconstructions has only a small impact on the size of the ice sheets at the end of the Eemian. This is in line with the results of Berger et al. (1998) for that time period. However, our results show that for the course of climatic variables such as temperatures during the simulation, it does matter which $\mathrm{CO}_{2}$ reconstruction is chosen.

In addition, applying the reconstruction according to Barnola et al. (1987) instead of Petit et al. (1999) in our model strengthens the impact of an interactive ocean on the Laurentide ice-sheet expansion. Vettoretti and Peltier (2003) pointed out that a reasonable simulation of present-day SSTs has a crucial impact on the high-latitude snow mass balance in a model. Taking these and other results together leads us to the conclusion that the quantitative contributions of individual parts of the climate system to a given climate change, in particular in the vicinity of a bifurcation, crucially depend not only on a thorough description of internal model processes but also on a reliable external forcing itself. Currently, ranking of ocean or vegetation impact on the LGI is thus impossible.

Acknowledgements

We are grateful to Ralf Greve for providing us with the ice-sheet model SICOPOLIS. The authors would like to thank Alexandra Jahn for technical assistance. The work was funded by a subcontract to project 01LD0041 (DEKLIM-EEM) of the Bundesministerium für Bildung und Forschung (BMBF) and it was partly funded by the Deutsche Forschungsgemeinschaft (DFG) project CL 178/2-1.

References

Barnola JM, Raynaud D, Korotkevich YS, Lorius C (1987) Vostok ice core provides 160,000-year record of atmospheric $\mathrm{CO}_{2}$. Nature 329: 408-414

Barnola JM, Raynaud D, Lorius C, Barkov NI (1999) Historical $\mathrm{CO}_{2}$ record from the Vostok ice core. In: Trends: A Compendium of Data on Global Change. Carbon Dioxide Information Analysis Center, Oak Ridge National Laboratory, Department of Energy, U.S., Oak Ridge, Tenn., U.S.A.

Berger A (1978) Long-term variations of daily insolation and Quaternary climatic changes. J Atm Sci 35: 2362-2367

Berger A (2000) The role of $\mathrm{CO}_{2}$, sea-level and vegetation during the Milankovitch-forced glacial-interglacial cycles. In: Bengtsson L (Ed.) Geosphere-Biosphere Interactions and Climate. Proceedings of the Workshop held at Pontifical Academy of Sciences. 
Berger A, Loutre MF, Gallée $\mathrm{H}$ (1998) Sensitivity of the LLN climate model to the astronomical and $\mathrm{CO}_{2}$ forcings over the last $200 \mathrm{ky}$. Clim Dyn 14: 615-629

Bonan G, Pollard D, Thompson S (1992) Effects of boreal forest vegetation on global climate. Nature 359: 716-718

Brovkin V, Ganopolski A, Claussen M, Kubatzki C, Petoukhov V (1999) Modelling climate response to histrocial land cover change. Glob Ecol Biogeog 8: 509-517

Brovkin V, Bendtsen J, Claussen M, Ganopolski A, Kubatzki C, Petoukhov V, Andreev A (2002) Carbon cycle, vegetation, and climate dynamics in the Holocene: Experiments with the CLIMBER-2 model. Glob Biogeochem Cyc 16(4): 1139, DOI 10.1029/2001GB001662

Brovkin V, Levis S, Loutre M-F, Crucifix M, Claussen M, Ganopolski A, Kubatzki C, Petoukhov V (2003) Stability analysis of the climate-vegetation system in the northern high latitudes. Clim Change 57: 119-138

Calov R, Ganopolski A, Petoukhov V, Claussen M, Greve R (2002) Large-scale instabilities of the Laurentide ice sheet simulated in a fully coupled climate-system model. GRL 29:2216, DOI 10.1029/2002GL016078

Calov R, Ganopolski A, Claussen M, Petoukhov V, Greve R (2005a) Transient simulation of the last glacial inception. Part I: Glacial inception as a bifurcation in the climate system. Clim Dyn 24 (6), 545-561, DOI 10.1007/s00382-005-0007-6

Calov R, Ganopolski A, Petoukhov V, Claussen M, Brovkin V, Kubatzki C (2005b) Transient simulation of the last glacial inception. Part II: Sensitivity and feedback analysis. Clim Dyn 24 (6), 563-576, DOI 10.1007/s00382-005-0008-5

Chappell J, Omura A, Esat T, McCulloch M, Pandolfi J, Ota Y, Pillans B (1996) Reconciliation of late Quaternary sea levels derived from coral terraces at Huon Peninsula with deep sea oxygen isotope records. EPSL 141: 227-236

Clark PU, Clague JJ, Curry BB, Dreimanis A, Hicock SR, Miller SR, Miller GH, Berger GW, Eyles N, Lamothe M, Miller BB, Mott RJ, Oldale RN, Stea RR, Szabo JP, Thorleifson LH, Vincent J-S (1993) Initiation and development of the Laurentide and Cordilleran ice sheets following the last interglaciation. Quat Sci Rev 12: 79-114

Claussen M, Kubatzki C, Brovkin V, Ganopolski A, Hoelzmann P, Pachur H-J (1999) Simulation of an abrupt change in Saharan vegetation in the mid-Holocene. Geophys Res Let 26(14): 2037-2040

Claussen M (2001) Biogeophysical feedbacks and the dynamics of climate. In: Schulze ED, Harrison SP, Heimann M, Holland EA, Lloyd J, Prentice IC, Schimel D (eds) Global Biogeochemical Cycles in the Climate System. Academic Press, San Diego, pp 61-71

Crowley TJ, Baum SK (1995) Is the Greenland ice sheet bistable ? Paleocean Curr 10(3): 357-363

Crucifix M, Loutre MF (2002) Transient simulations over the last interglacial period (126-115 kyr BP) : feedback and forcing analysis. Clim Dyn 19: 417-433

Cuffey KM, Marshall SJ (2000) Substantial contribution to sea-level rise during the last interglacial from the Greenland ice sheet. Nature 406: 591-594

De Noblet NI, Prentice IC, Joussaume S, Texier D, Botta A, Haxeltine A (1996) Possible role of atmospherebiosphere interactions in triggering the last glaciation. GRL 23(22): 3191-3194

Dong B, Valdes PJ (1995) Sensitivity studies of northern hemisphere glaciation using an atmospheric general circulation model. J Clim 8: 2471-2496

Gallimore RG, Kutzbach JE (1996) Role of orbitally induced changes in tundra area in the onset of glaciation. Nature 381: 503-505

Ganopolski A, Rahmstorf S, Petoukhov V, Claussen M (1998a) Simulation of modern and glacial climates with a coupled global model of intermediate complexity. Nature 391: 351-356

Ganopolski A, Kubatzki C, Claussen M, Brovkin V, Petoukhov V (1998b) The influence of vegetationatmosphere-ocean interaction on climate during the mid-Holocene. Science 280: 1916-1919 
Ganopolski A, Petoukhov V, Rahmstorf S, Brovkin V, Claussen M, Eliseev A, Kubatzki C (2001) CLIMBER-2: a climate system model of intermediate complexity. Part II: model sensitivity. Clim Dyn 17: 735-751

Greve R (1997) A continuum-mechanical formulation for shallow polythermal ice sheets. Phil Trans R Soc Lond A355: 921-974

Harvey LDD (1989) Milankovitch forcing, vegetation feedback, and North Atlantic deep-water formation. J Clim 2: 800-815

Kageyama M, Charbit S, Ritz C, Khodri M, Ramstein G (2004) Quantifying ice-sheet feedbacks during the last glacial inception. Geophys Res Let 31: L24203, DOI 10.1029/2004GL021339

Khodri M, Leclainche Y, Ramstein G, Braconnot P, Marti O, Cortijo E (2001) Simulating the amplification of orbital forcing by ocean feedbacks in the last glaciation. Nature 410: 570-574

Kubatzki C, Montoya M, Rahmstorf S, Ganopolski A, Claussen M (2000) Comparison of a coupled global model of intermediate complexity and an AOGCM for the last interglacial. Clim Dyn 16: 799-814.

Marshall SJ, and Clarke GKC (1999) Ice sheet inception: subgrid hypsometric parameterization of mass balance in an ice sheet model. Clim Dyn 15: 533-550

Meissner KJ, Weaver AJ, Matthews HD, Cox PJ (2003) The role of land-surface dynamics in glacial inception: a study with the UVic Earth System Model. Clim Dyn 21(7-8): 515-537

North Greenland Ice Core Project members (2004) High-resolution record of northern hemisphere climate extending into the last interglacial period. Nature 431: 147-151

Petit JR, Jouzel J, Raynaud D, Barkov NI, Barnola J-M, Basile I, Bender M, Chappellaz J, Davis M, Delaygue G, Delmotte M, Kotlyakov VM, Legrand M, Lipenkov VY, Lorius C, Pépin L, Ritz C, Saltzman E, Stievenard M (1999) Climate and atmospheric history of the past 420,000 years from the Vostok ice core, Antarctica. Nature 399: 429-436

Petoukhov V, Ganopolski A, Brovkin V, Claussen M, Eliseev A, Kubatzki C, Rahmstorf S (2000) CLIMBER-2: A climate system model of intermediate complexity. Part I: Model description and performance for present climate. Clim Dyn 16: 1-17

Rahmstorf S, Ganopolski A (1999) Long-term global warming scenarios computed with an efficient coupled climate model. Clim Change 43: 353-367

Siddall M, Rohling EJ, Almogi-Labin A, Hemleben Ch, Meischner D, Schmelzer I, Smeed DA (2003) Sealevel fluctuations during the last glacial cycle. Nature 423: 853-858

Stirling CH, Esat TM, Lambeck K, McCulloch MT (1998) Timing and duration of the Last Interglacial: evidence for a restricted interval of widespread coral reef growth. EPSL 160: 745-762

Stocker T, Wright D, Mysak L (1992) A zonally averaged, coupled ocean-atmosphere model for paleoclimate studies. J Clim 5: 773-797

Vettoretti G, Peltier WR (2003) Post-Eemian glacial inception. Part I: The impact of summer seasonal temperature bias. J Clim 16(6): 889-911

Vettoretti G, Peltier WR (2004) Sensitivity of glacial inception to orbital and greenhouse gas climate forcing. Quat Sci Rev 23: 499-519

Waelbroeck C, Labeyrie L, Michel E, Duplessy JC, McManus JF, Lambeck K, Balbon E, Labracherie M (2002) Sea-level and deep water temperature changes derived from benthic foraminifera isotopic records. Quat Sci Rev 21: 295-305

Wang Z, Mysak LA (2002) Simulation of the last glacial inception and rapid ice sheet growth in the McGill Paleoclimate Model. GRL 29(23): 2102, DOI 10.1029/2002GL015120

Yoshimori M, Reader MC, Weaver AJ, McFarlane NA (2002) On the causes of glacial inception at 116 kaBP. Clim Dyn 18: 383-402 
Tab. 1: Experiments presented in this study. The inland-ice model is always interactively coupled.

Fig. 1: Maximum summer insolation at $65^{\circ} \mathrm{N}\left[\mathrm{W} / \mathrm{m}^{2}\right]$ (left axis, thick solid line; thick dashed line represents present-day insolation; Berger 1978) and atmospheric $\mathrm{CO}_{2}$ concentration [ppmv] (right axis, thin solid line Petit et al. 1999; thin dashed line Barnola et al. 1987) over the Eemian and LGI.

Fig. 2: Greenland ice area $\left[10^{6} \mathrm{~km}^{2}\right]$ in two equilibrium simulations for $128 \mathrm{kyr} \mathrm{BP}$ and an equilibrium simulation of pre-industrial climate (CTR, dotted). The Eemian simulations were either initiated with modelled pre-industrial inland ice distribution (EQ128k, solid) or with no inland ice in the northern hemisphere (EQ128k_0, dashed).

Fig. 3: Differences in annual a) sea-ice fraction [\%] and b) tree fraction [\%] between the equilibrium simulations EQ128k and CTR of the Eemian and pre-industrial climate.

Fig. 4: a) Ice volume $\left[10^{6} \mathrm{~km}^{3}\right]$ (left axis, thick solid line) and area $\left[10^{6} \mathrm{~km}^{2}\right]$ (right axis, thin dashed line) in North America and b) global annual temperature $\left[{ }^{\circ} \mathrm{C}\right]$ in the transient simulation AOVI over the Eemian and LGI.

Fig. 5: Ice-sheet thickness [m] in the transient simulation AOVI at $113 \mathrm{kyr} \mathrm{BP}$.

Fig. 6: a) Northern hemispheric without Greenland and b) Greenland ice area $\left[10^{6} \mathrm{~km}^{2}\right]$ in the simulation AOVI (solid) and in a simulation, in which no inland ice in the northern hemisphere was assumed at the beginning of the simulation (AOVI_0, dashed).

Fig. 7: Inland-ice area $\left[10^{6} \mathrm{~km}^{2}\right]$ in North America (top row) and Greenland (bottom row) over the Eemian and LGI in simulation AOVI (black) and when fixing the state of the Earth's surface to their pre-industrial (left column) and Eemian (right column) conditions, respectively; ocean interactive but vegetation fixed (blue), vegetation interactive but ocean fixed (green), fixed ocean and vegetation (red).

Fig. 8: Global annual temperature $\left[{ }^{\circ} \mathrm{C}\right]$ over the Eemian and LGI in simulation AOVI (black) and when fixing the state of the Earth's surface to their a) pre-industrial and b) Eemian conditions, respectively; ocean interactive but vegetation fixed (blue), vegetation interactive but ocean fixed (green), fixed ocean and vegetation (red).

Fig. 9: a) Global annual changes in near-surface temperature $\left[{ }^{\circ} \mathrm{C}\right]$ and b) changes of the inland-ice area $\left[10^{6} \mathrm{~km}^{2}\right]$ in North America over the Eemian and LGI for simulations of the fully coupled model with the $\mathrm{CO}_{2}$ reconstruction according to Petit et al. (1999) (AOVI, thick black) and Barnola et al. (1987) (AOVI_bar, thin black). For the inland-ice area, also results of simulations with fixed pre-industrial surface conditions and using the $\mathrm{CO}_{2}$ data according to Barnola et al. (1987) are shown; ocean interactive but vegetation fixed (AOI0_bar, blue), vegetation interactive but ocean fixed (AVI0_bar, green), fixed ocean and vegetation (AI0_bar, red). 


\begin{tabular}{|c|c|c|c|c|c|}
\hline Experiment & Orbital parameters & $\mathrm{CO}_{2}$ & Initial conditions & Ocean & Vegetation \\
\hline CTR & PD & $280 \mathrm{ppmv}$ & no inland ice $\mathrm{NH}$ & interactive & interactive \\
\hline EQ128k & 128 kyr BP & 277 ppmv & CTR & interactive & interactive \\
\hline EQ128k_0 & 128 kyr BP & $277 \mathrm{ppmv}$ & CTR, no inland ice $\mathrm{NH}$ & interactive & interactive \\
\hline EQ128k_bar & 128 kyr BP & 273 ppmv & CTR & interactive & interactive \\
\hline AOVI & 128 to $100 \mathrm{kyr} \mathrm{BP}$ & Petit & EQ128k & interactive & interactive \\
\hline AOVI_0 & 128 to $100 \mathrm{kyr} \mathrm{BP}$ & Petit & EQ128k, no inland ice $\mathrm{NH}$ & interactive & interactive \\
\hline AVI0 & 128 to $100 \mathrm{kyr} \mathrm{BP}$ & Petit & EQ128k & CTR & interactive \\
\hline AOI0 & 128 to $100 \mathrm{kyr} \mathrm{BP}$ & Petit & EQ128k & interactive & CTR \\
\hline AI0 & 128 to $100 \mathrm{kyr} \mathrm{BP}$ & Petit & EQ128k & CTR & CTR \\
\hline AVI128 & 128 to $100 \mathrm{kyr} \mathrm{BP}$ & Petit & EQ128k & EQ128 & interactive \\
\hline AOI128 & 128 to $100 \mathrm{kyr} \mathrm{BP}$ & Petit & EQ128k & interactive & EQ128 \\
\hline AI128 & 128 to $100 \mathrm{kyr} B P$ & Petit & EQ128k & EQ128 & EQ128 \\
\hline AOVI_bar & 128 to $100 \mathrm{kyr} B P$ & Barnola & EQ128k_bar & interactive & interactive \\
\hline AVIO_bar & 128 to $100 \mathrm{kyr} \mathrm{BP}$ & Barnola & EQ128k_bar & CTR & interactive \\
\hline AOI0_bar & 128 to $100 \mathrm{kyr} \mathrm{BP}$ & Barnola & EQ128k_bar & interactive & CTR \\
\hline AI0_bar & 128 to $100 \mathrm{kyr} B P$ & Barnola & EQ128k_bar & CTR & CTR \\
\hline
\end{tabular}

Tab. 1: Experiments presented in this study. The inland-ice model is always interactively coupled. 


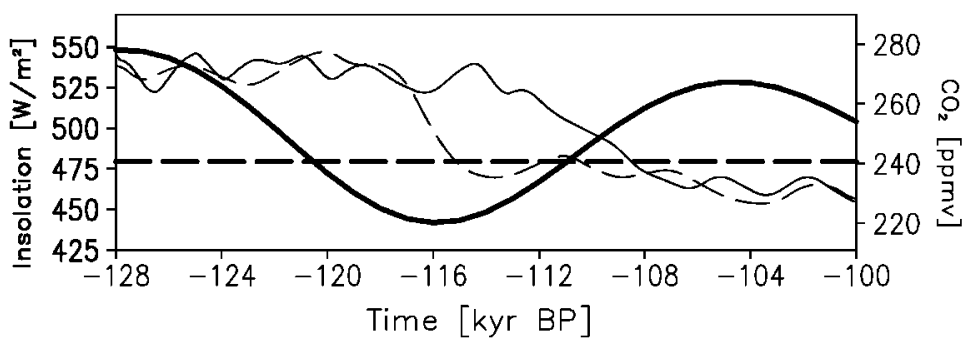

Fig. 1: Maximum summer insolation at $65^{\circ} \mathrm{N}\left[\mathrm{W} / \mathrm{m}^{2}\right]$ (left axis, thick solid line; thick dashed line represents present-day insolation; Berger 1978) and atmospheric $\mathrm{CO}_{2}$ concentration [ppmv] (right axis, thin solid line Petit et al. 1999; thin dashed line Barnola et al. 1987) over the Eemian and LGI. 


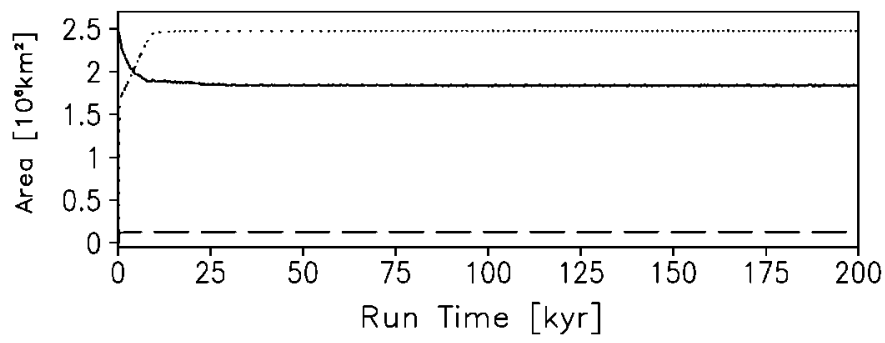

Fig. 2: Greenland ice area $\left[10^{6} \mathrm{~km}^{2}\right]$ in two equilibrium simulations for $128 \mathrm{kyr} \mathrm{BP}$ and an equilibrium simulation of pre-industrial climate (CTR, dotted). The Eemian simulations were either initiated with modelled pre-industrial inland ice distribution (EQ128k, solid) or with no inland ice in the northern hemisphere (EQ128k_0, dashed). 

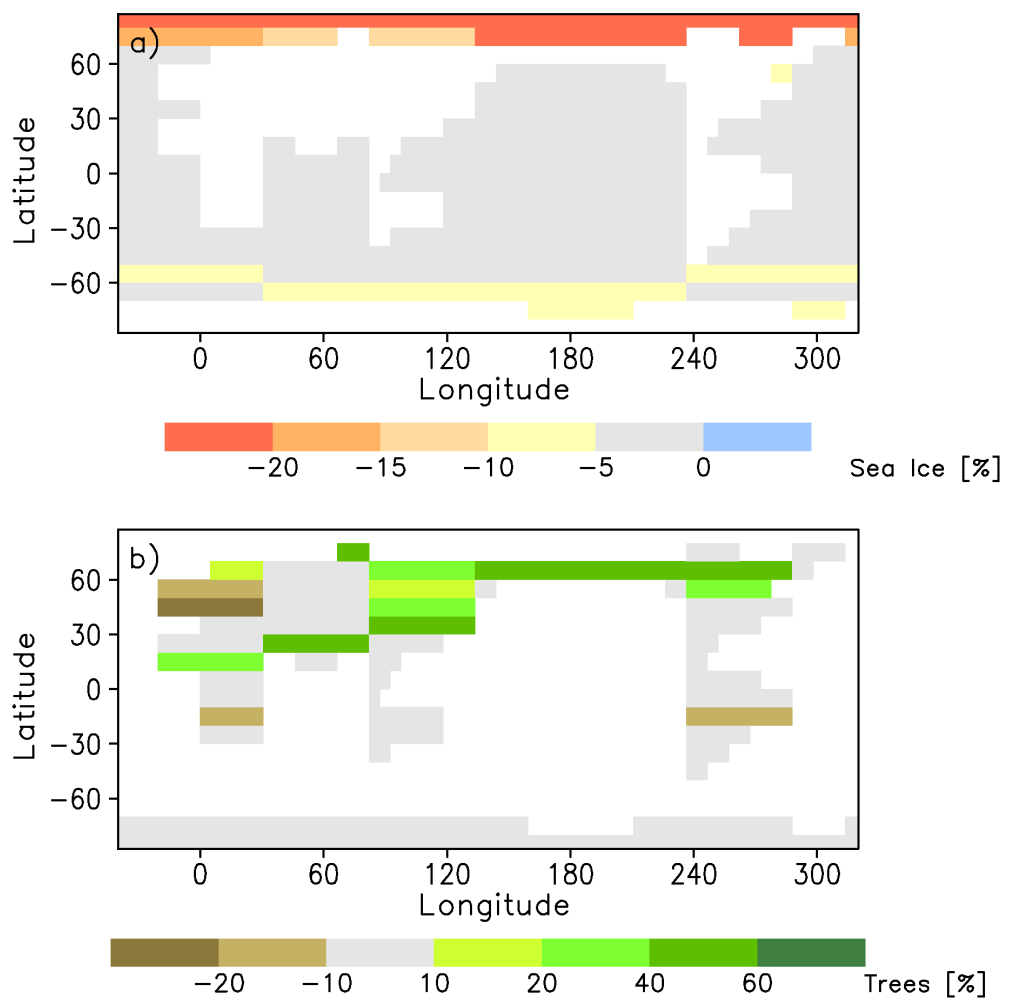

Fig. 3: Differences in annual a) sea-ice fraction [\%] and b) tree fraction [\%] between the equilibrium simulations EQ128k and CTR of the Eemian and pre-industrial climate. 

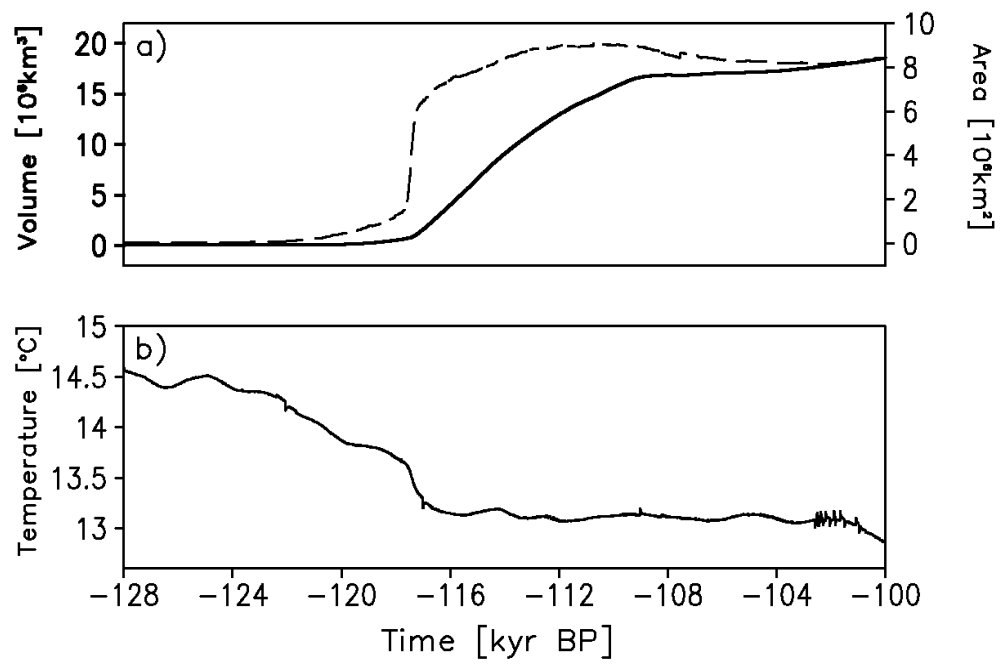

Fig. 4: a) Ice volume $\left[10^{6} \mathrm{~km}^{3}\right]$ (left axis, thick solid line) and area $\left[10^{6} \mathrm{~km}^{2}\right]$ (right axis, thin dashed line) in North America and b) global annual temperature $\left[{ }^{\circ} \mathrm{C}\right]$ in the transient simulation AOVI over the Eemian and LGI. 
lce-sheet thickness at $113 \mathrm{kyr}$ BP [m]

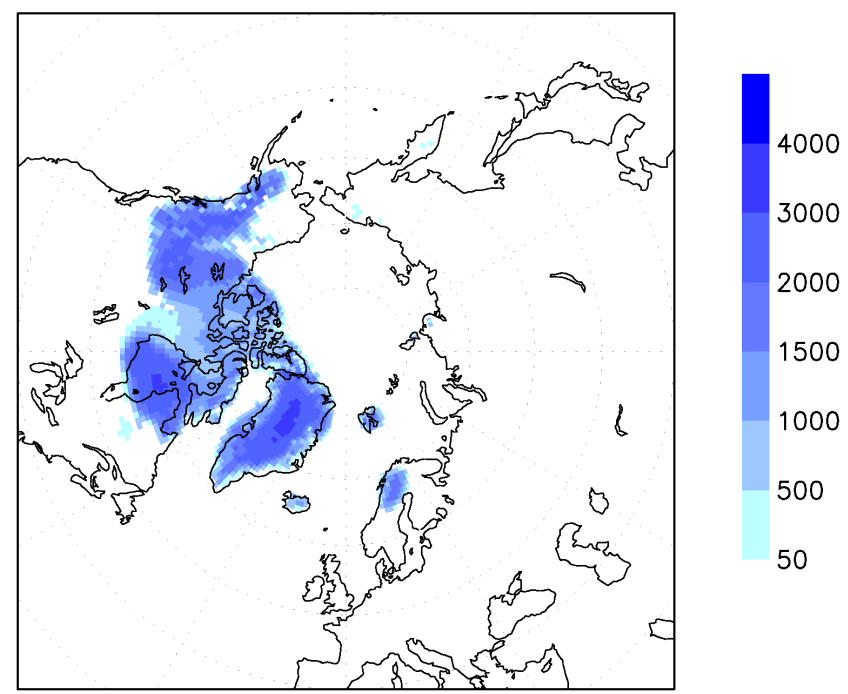

Fig. 5: Ice-sheet thickness [m] in the transient simulation AOVI at $113 \mathrm{kyr}$ BP. 

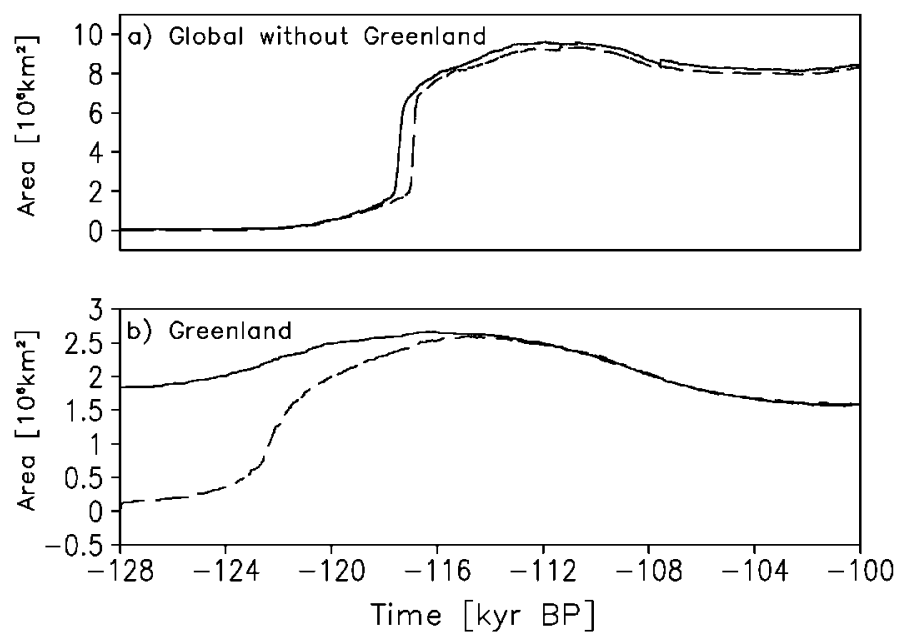

Fig. 6: a) Northern hemispheric without Greenland and b) Greenland ice area $\left[10^{6} \mathrm{~km}^{2}\right]$ in the simulation AOVI (solid) and in a simulation, in which no inland ice in the northern hemisphere was assumed at the beginning of the simulation (AOVI_0, dashed). 

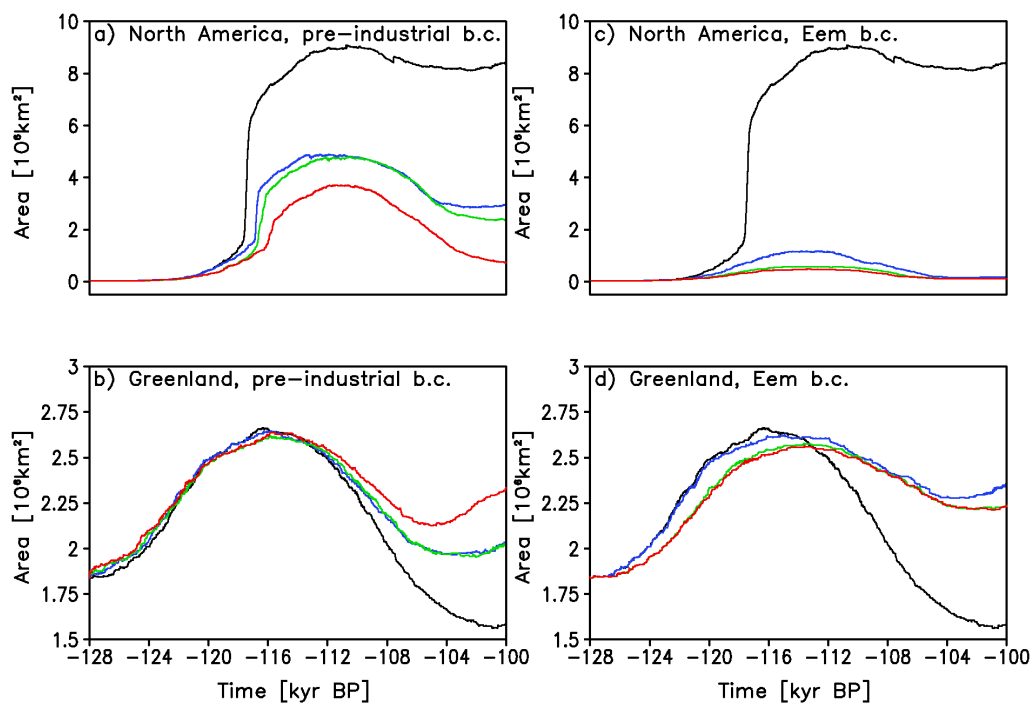

Fig. 7: Inland-ice area $\left[10^{6} \mathrm{~km}^{2}\right]$ in North America (top row) and Greenland (bottom row) over the Eemian and LGI in simulation AOVI (black) and when fixing the state of the Earth's surface to their pre-industrial (left column) and Eemian (right column) conditions, respectively; ocean interactive but vegetation fixed (blue), vegetation interactive but ocean fixed (green), fixed ocean and vegetation (red). 

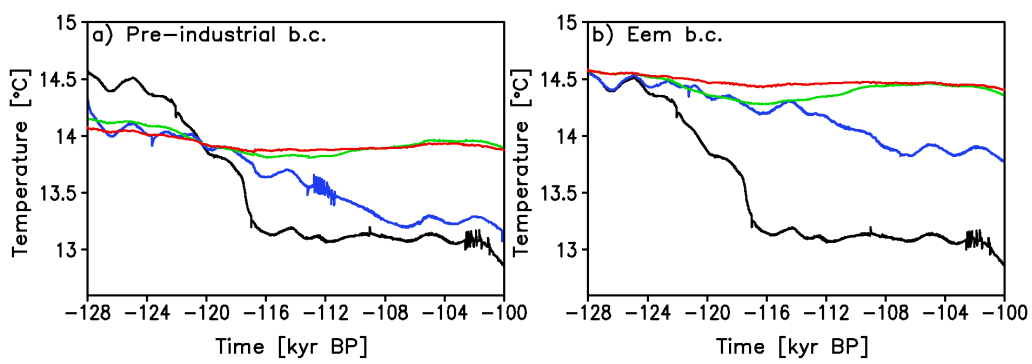

Fig. 8: Global annual temperature $\left[{ }^{\circ} \mathrm{C}\right]$ over the Eemian and LGI in simulation AOVI (black) and when fixing the state of the Earth's surface to their a) pre-industrial and b) Eemian conditions, respectively; ocean interactive but vegetation fixed (blue), vegetation interactive but ocean fixed (green), fixed ocean and vegetation (red). 

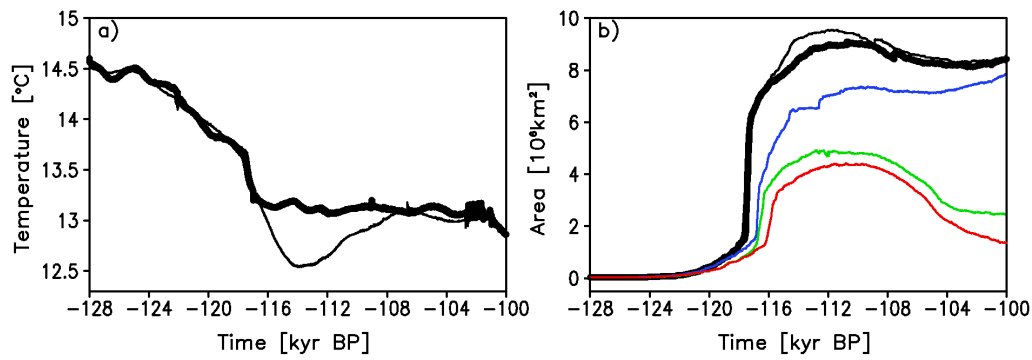

Fig. 9: a) Global annual near-surface temperature $\left[{ }^{\circ} \mathrm{C}\right]$ and b) inland-ice area $\left[10^{6} \mathrm{~km}^{2}\right]$ in North America over the Eemian and LGI for simulations of the fully coupled model with the $\mathrm{CO}_{2}$ reconstruction according to Petit et al. (1999) (AOVI, thick black) and Barnola et al. (1987) (AOVI_bar, thin black). For the inland-ice area, also results of simulations with fixed preindustrial surface conditions and using the $\mathrm{CO}_{2}$ data according to Barnola et al. (1987) are shown: ocean interactive but vegetation fixed (AOI0_bar, blue), vegetation interactive but ocean fixed (AVI0_bar, green), fixed ocean and vegetation (AI0_bar, red). 